\title{
TOWARDS GREEN SMART CITIES: IMPORTANCE OF URBAN FORESTRY AND URBAN VEGETATION
}

\author{
Zennure UÇAR ${ }^{1 *}$, Abdullah E. AKAY², Ebru BİLIĊं ${ }^{3}$ \\ 1 Duzce University, Faculty of Forestry, Forest Engineering Department, 81620, Duzce, TURKEY- zennureucar@ duzce.edu.tr \\ 2 Bursa Technical University, Faculty of Forestry, Forest Engineering Department, 16310, Bursa, TURKEY- \\ abdullah.akay@btu.edu.tr \\ 3 Giresun University, Dereli Vocational School, 28950, Giresun, TURKEY - ebru.bilici@ giresun.edu.tr
}

Commission VI, WG VI/4

KEY WORDS: Urban forestry, urban vegetation, green infrastructure, sustainability, urban technology, smart monitoring, smart cities

\begin{abstract}
:
More than half of the total world's population lives in urban areas, and it is expected that $66 \%$ of all them will live in urban areas by 2050. The population growth and continuing urbanization in the world cause many social, economic, technical, and organizational problems related to transportation, businesses, communication networks, services, and utilities that can risk the cities' economic and environmental sustainability. Recently, a smart city concept has been developed to provide a solution to improve citizens' quality of life in urban areas with the adoption of smart and digital technologies and infrastructure for energy, water, mobility, buildings, and government. The smart city concept considers "zero vision" that refers to the use of smart city technologies, Information and Communication Technologies (ICTs) and Internet of Things (IoT) tools, to minimize negative impacts (i.e., zero traffic accident, zero $\mathrm{CO} 2$ emission, zero waste, zero crime) in the cities. However, the research in this zero-vision approach mainly focused on transportation and energy. Urban forestry and urban vegetated areas in the cities inherently provide benefits such as reducing air pollution, urban heat island effects, and flood risk and increasing the water quality, aesthetic value, and value of the property that improve citizens' quality of life. The smart city concept switched towards to sustainable smart city concept that takes into account the services provided by urban forestry and urban vegetation. In this study, the shifts in the smart city concept towards the sustainable smart city, the role of the urban forestry and urban vegetation in this shift was presented. Also, ICTs and IoT tools specifically designed for monitoring, assessing, and managing urban forestry and urban vegetation was reviewed.
\end{abstract}

\section{INTRODUCTION}

Today, it has been reported by the UN that more than half of the population in the world lives in urban areas (United Nations, 2015). The overall growth of the world's population and continuing urbanization increase complexity in cities, including a huge number of interrelated citizens, businesses, different forms of transports, communication networks, services, and utilities (Neirotti et al., 2013). Although urbanization has become attractive by providing many opportunities including employment, education and cultural and social amenities, it also brings along the increased need for infrastructure such as educational facilities, health services, transportation services, demand for housing and roads, and cultural amenities (United Nations, 2015; Mundoli et al., 2017; Okai et al., 2018). The cities generate about $80 \%$ of Global Gross Domestic Product (GPD); however, they consume around $70 \%$ of the global energy usage and produce $70-80 \%$ of Greenhouse Gas (GHG) emission that causes climate change (Lee et al., 2014; Sethi, 2015; Okai et al., 2018; Silva et al., 2018). This causes different kinds of social, economic, technical, and organizational problems that can risk the cities' economic and environmental sustainability (Neirotti et al., 2013; Yigitcanlar, 2015; Mundoli et al., 2017; Russo and Cirella, 2018).

Rapid urbanization has started to significantly impact the quality of life of citizens along with economic, social and environmental changes (Yigitcanlar, 2015; Anguluri and Narayanan, 2017; Mobilia and Longobardi, 2017). Due to the global urbanization trend, the demand for sustainability in the cities rises. Hence, the cities have begun using smart technologies to manage the current and future challenges of this rapid urbanization (Mobilia and Longobardi, 2017). Smart city concept has emerged in last few decades to address these challenges and generate solutions for the efficient city managements and urban developments (Yigitcanlar, 2015; Mobilia and Longobardi, 2017; Mundoli et al., 2017).

\subsection{Smart city concept}

There are many definitions found in the literature for the smart city term. A review by Albino et al (2015) provides more detail about the definitions, dimensions, and evaluation of the smart cities concept through time. Smart city definitions include six main components: smart "governance, economy, people, mobility, living and environment" (Lombardini et al., 2012) while assessing the performance of the smart cities (Yigitcanlar, 2015). When the term first was used in the 1990s, it was alternatively replaced with the digital city, wired city, cyber city, or intelligent city, which mainly focused on the importance of new Information and Communication Technologies (ICT) and the Internet of Thing (IoT) along with modern infrastructures within cities. These tools integrated into the urban environment for monitoring, assessing, and managing city problems and services (i.e., lack of the public service- health, education, transportation, food, and freshwater security-, organizing traffic, population growth, and its pressure on land use land cover) (Lee et al., 2014). However, the smart city 
concept is differentiated from these alternative city terms by focusing on people and enhancing their quality of life in urban areas using ICT and IoT as tools while urging citizen participation, engagement, and mobilization (Neirotti et al., 2014; Albino et al., 2015; Yigitcanlar, 2015; Ercoşkun, 2016; Silva et al., 2018; Nitowslawski et al., 2019).

Recently, the adoption of ICTs and IoT tools and infrastructure for energy, water, mobility, buildings, and government, which provides a solution to improve citizens' quality of life in urban areas, has brought out the "zero vision" in the smart city concept. It generally refers to minimize negative impacts (i.e., zero traffic accident, zero $\mathrm{CO} 2$ emission, zero waste, zero crime) in the cities due to urbanization, and to become fully sustainable (Sethi, 2015; Wachsmuth and Angelo, 2018; Alsamhi et al., 2019). This zero-vision integrated with smart sustainable city concept started to be applied by several smart city municipalities in the world. For example, in the USA (in New York, Boston, and Seattle), and Sweeden, zero vision was adopted into road safety to minimize the number of the death and serious injuries based on the traffic accident particularly (Angelidou et al., 2017). Another well-known example of a zero vision is to switch to solar-powered streetlights with LEDs. That does not only reduce the grid connection cost, but it also has Wi-Fi hot spot capabilities and other IoT tools such as monitoring air pollution, $\mathrm{CO} 2$ emission, traffic, weather with a sensor embedded to the poles. Toronto applied smart city initiatives by incorporating solar and wind power into city design and reduce neighborhood emission by $75 \%$ (City of Hamilton, 2014). In Highland Park, Michigan, switching to solar-powered streetlights reduced energy use $45-50 \%$ compared to grid lights (Tuerk, 2019). In San Francisco, solar power has started to use as a charge plug station for the electric vehicle. Hence, they will both reduce $\mathrm{CO} 2$ emissions of the car and the cost of energy use and energy consumption by $50 \%$ (Lee at al., 2014; Silva et al., 2018).

In addition to this, solar-powered energy panels have been increasingly integrated into the construction of energy sufficient and eco-friendly buildings in smart sustainable city initiatives around the world. In general, population growth in urban areas requires constructing a building for basic human needs such as sheltering and providing services (i.e., education, health, transportation, government) or providing job opportunities (Wachsmuth and Angelo, 2018). With the use of these zero vision initiatives, energy consumption in the buildings due to electricity use (i.e., lightning, cooling, heating) can be reduced around $50 \%$. These employed initiatives showed that the research and practices in the zero-vision approach mainly focused on transportation and energy use in a smart sustainable city. However, a smart sustainable city concept requires the incorporation of many disciplines, including urban planning, engineering, data, computer, strong economic prospect, and human well-being (Lee et al., 2014). Nowadays, the design of the buildings for smart sustainable city initiatives recently encourages the alternatives to reduce energy uses and $\mathrm{C} 02$ emissions such as using natural light, harvesting of rainwater with green rooftop, or using the green wall for cooling effect. There is an observed shift from only using ICT and IoT tools and technologies and economic outcomes of these to improve quality of life to integrating natural-based solutions into technology and tools to improve human well-being with a more livable environment in the smart city concept over the time.

\section{IMPORTANCE OF THE URBAN FORESTRY AND URBAN GREENING IN SMART CITIES}

Urban forestry and urban greening areas offers essential biophysical and socioeconomic benefits to both human and the cities, including but not limited to reduce energy use, facilitate cooling effects, improve water and air quality, and improve biodiversity and wildlife habitat. Urban vegetation also provides recreational opportunities and aesthetic values that improve health and the overall enjoyment and increase the value of neighborhoods (Nowak et al., 2010; Richardson and Moskal, 2014; Anguluri and Narayanan, 2017; Mundoli et al., 2017; Ucar et al., 2018). There are extensive research and documents on the importance of the urban forestry and greening area and its benefits to human wellbeing, and contribution to the economic value of the city (Anguluri and Narayanan 2017). Even though the component of the smart city concept, including environment, people, and living, seems to consider urban forestry and greening areas or urban green infrastructure, the focus was the use of the ICT and IoT tools to make the city more intelligent and smart, not green and sustainable especially, when the first the smart city concept arose (Albino et al., 2015; Wachsmuth and Angelo, 2018). For instance, India aims to develop 100 smart cities to provide smart solutions for egovernance, waste management, water, and energy use, but this plan did not mention the urban forestry and urban green area management (Datta, 2015). Also, Canada initiated Smart Cities Challenges in 2017 and received around 130 applications that fail to collaborate with urban forestry and urban greening (Nitowslawski et al., 2019).

The role of the urban forestry and urban green areas becomes crucial due to rapid population growth in the cities and slowly integrated into the smart city concept. Mobilia and Longobardi (2017) and Shafique et al. (2018) used a green roof for smart stormwater management in urban areas. The green roof provides several benefits, including sound and thermal isolation, reducing urban heat island effect, and air pollution in addition to reducing flood risk in urban. The result from both studies indicated that green roof approaches are effective in the reduction of total runoff volume in urban areas. Also, new city design in most of the smart cities in Soutasia countries, Austria, North America, and some European counties encourage vertical greening and Biophilic design due to conversion from vegetated areas to development areas in the city (Russo and Cirella, 2018) (Figure 1). This design will not only connect people with, providing recreational opportunities and aesthetic values that improve health and overall enjoyment but also will reduce energy consumption by cooling effect and reduction of urban heat island, improve air and water quality and biodiversity (Dowton et al., 2016; Anguluri and Narayanan, 2017; Russo and Cirella, 2018). Overall, with advanced technology and changing demands toward the greener city, the concepts and initiatives could bring urban forestry and urban greening into the planning and operation of smart cities. 

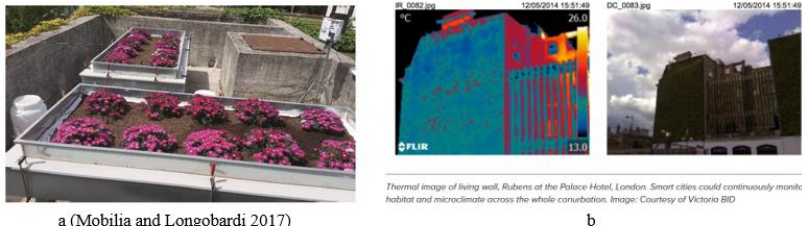

a (Mobilia and Longobardi 2017)
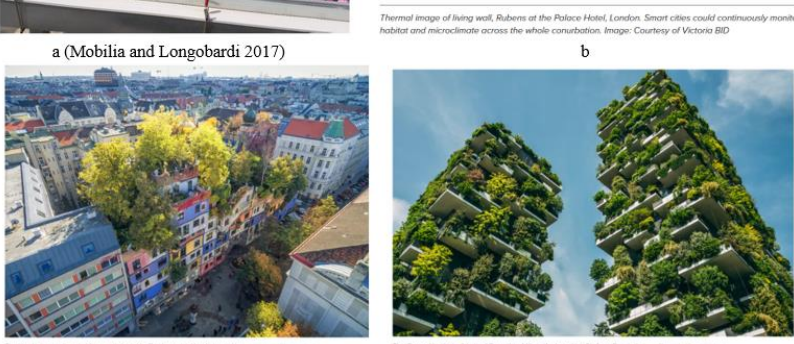

Figure 1. Examples for Biophilic design within smart sustainable city a) green roof, b) living wall, c and d) vertical greening

\section{ICT AND IOT TRENDS AND TECHNOLOGIES IN URBAN FORESTRY AND URBAN GREENING}

Advanced technology has already been applied to monitoring, assessing, and analysing environmental and natural resource management. These smart technologies include remote sensing technology (i.e., Hyperspectral imagery, LiDAR) that enables us to map and assess species and individual trees by integrating with machine learning, and google earth engine is a cloud-based application that can monitor and map land use land cover and the vegetation changes in a global scale. Nowadays, unmanned aerial vehicle (UAV) help through surveying, fertilizer spraying, and seedling, and detecting disasters (fires, infestation, or windbreak) in forested areas (Nitoslawski et al., 2019; Gabrys, 2020). Smart technologies such as wireless sensors and Radio-Frequency Identification (RFID) microchip have been employed to collect information about vegetation and to share the information through web-based platforms (Luvisi and Lorenzinin, 2014; Alsamhi et al., 2019). These smart technologies provide big data sources that can be shared with the municipality to manage urban forestry and greening areas effectively. They have been used to monitor urban green areas for the sustainability of natural resources within the city.

The number of applied ICT and IoT technology and initiatives related to the sustainability of urban forestry and urban greening have been launched around the world. Some of them is explained as an example below. Amsterdam (NL) developed the Green City Watch initiative using a geospatial artificial intelligence to monitor urban green areas continuously. Chicago (USA) uses sensors and cloud-based analytics to measure the performance of the various green pilot areas to designing feature green areas. Treescount initiatives in New York (USA) used VGI over 2,300 within a year for tree inventory, including measurement and identification of every single tree, and recording damages on the trunk (Nitoslawski et al., 2019). All this information provides opportunities to monitor and assess forest composition, structure, mitigation, and detect heavily damage trees. The use of smart technologies can reduce urban forestry and greening management costs and time by employing volunteered geographic information (VGI).

i-Tree is a well-known web-based urban forest canopy cover monitoring and assessment tool. It was developed by U.S. Forest Service and offers several desktops and web-based applications (Figure 2). With these innovative applications and tools, managers can quantify ecosystem services and benefits values of community trees and forests, including pollution mitigation, carbon sequestration and storage, and run-off reduction, at multiple scales (Hirabayashi et al., 2011). Some of the i-Tree applications also enable individual tree inventories within urban areas (Figure 2).

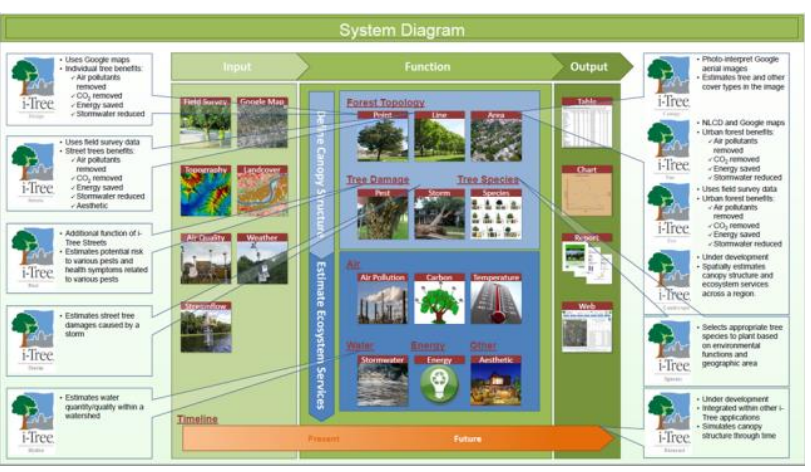

Figure 2. i-Tree desktop and web-based applications and system diagram by Hirabayashi et al. (2011).

OpenTreeMap is another open-source mapping platform that has been used for tree inventory and tree canopy cover estimation in major cities. Both web-based tools calculate ecosystem benefits from collected data and report any issues related to urban trees by using the VGI system (Figure 3a). The Nature Conservancy developed Healthy Trees Healthy City (HTHC) web application based on VGI. The aim is to improve the quality of life in the community through planting, care, neighbourhood. They wanted to engage the community for a sustainable green future. Likewise, the Seattle Department of Transportation (SDOP) developed an application for urban forestry inventory (Figure $3 b$ ). The aim is that with correct and updated tree inventory data, maintenance requirements can map more efficiently such as schedules for watering trees, and plan for better species diversity in the future.
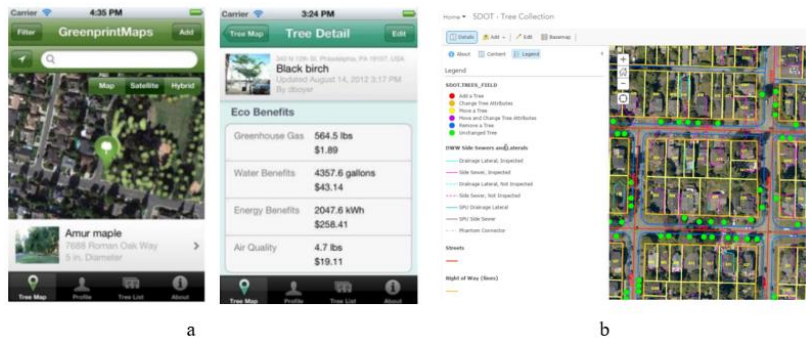

Figure 3. a) The views from OpenTreeMap application, b) the view from Seattle Department of Transportation (SDOP) application.

\section{CONCLUSION}

In this paper, the smart city concept was briefly explained by addressing trend changes in the concept over time. The emphasis of the concept is to improve the quality of life of the citizen in urban areas by using smart and digital technologies (ICTs and IoT) and infrastructure for energy, water, mobility, buildings, and government. New approaches such as zero vision or sustainability were added to the smart city concept to 
minimize negative impacts (i.e., zero traffic accident, zero $\mathrm{CO} 2$ emission, zero waste, zero crime) in the city while meeting increased human demands. This paper also presented the importance and benefits of urban forestry and urban greening and how it can incorporate into the smart city concept. Also, some ICT and IoT tools specifically designed for monitoring and assessing the inherent benefits of urban forestry and urban greening were reviewed. It can be stated that the use of ICT and IoT tools can help to manage urban forestry and urban greening areas and reduce management costs and time by employing VGI.

\section{REFERENCES}

Albino, V., Berardi, U., Dangelico, R. M. (2015). Smart cities: Definitions, dimensions, performance, and initiatives. Journal of urban technology, 22(1), 3-21.

Angelidou, M., Psaltoglou, A., Komninos, N., Kakderi, C., Tsarchopoulos, P., Panori, A. (2018). Enhancing sustainable urban development through smart city applications. Journal of Science and Technology Policy Management.

Anguluri, R., Narayanan, P. (2017). Role of green space in urban planning: Outlook towards smart cities. Urban Forestry \& Urban Greening, 25, 58-65.

City of Hamilton "Horizon Utilities Corporation's Street Light Rate Class Analysis (REF EB-2014-0002) Performed for Weirfoulds LLP. Accessed 01 September 2020

Datta, A. (2015). A 100 smart cities, a 100 utopias. Dialogues in Human Geography, 5(1), 49-53.

D.J. Nowak, S.M. Stein, P.B. Randler, E.J. Greenfield, S.J. Comas, M.A. Carr, R.J. Alig (2010). Sustaining America's Urban Trees and Forests. General Technical Report NRS-62 U.S Department of Agriculture, Forest Service, Northern Research Station, State and Private Forestry, Newtown Square, PA

Downton, P., Jones, D., Zeunert, J. (2016, November). Biophilia in urban design: patterns and principles for smart Australian cities. In Smart Cities for 21st Century Australia: Proceedings of the 9th International Urban Design Conference (IUDC) (pp. 7-9).

Ercoşkun, Ö. Y. (2016). Ultimate ICT Network in Turkey For Smart Cities. Journal of Planning, 26(2), 130-146.

Gabrys, J. (2020). Smart forests and data practices: From the Internet of Trees to planetary governance. Big Data \& Society, 7(1), 2053951720904871.

Hirabayashi, S., Nowak, D., Endreny, T. A., Kroll, C., Maco, S. (2011). i-Tree: Tools to assess and manage structure, function, and value of community forests. AGUFM, 2011, B21B-0263.

Lee, J., R. Phaal, S. Lee. 2013. "An Integrated Service devicetechnology Roadmap for Smart City Development." Technological Forecasting and Social Change 80: 286-306. doi:10.1016/j.techfore.2012.09.020.

Lee, J. H., Hancock, M. G., Hu, M. C. (2014). Towards an effective framework for building smart cities: Lessons from Seoul and San Francisco. Technological Forecasting and Social Change, 89, 80-99.
Lombardi, P., Giordano, S., Farouh, H., Yousef, W. (2012). Modelling the smart city performance. Innovation: The European Journal of Social Science Research, 25(2), 137-149.

Luvisi, A., Lorenzini, G. (2014). RFID-plants in the smart city: Applications and outlook for urban green management. Urban forestry \& urban greening, 13(4), 630-637.

Mobilia, M., Longobardi, A. (2017, July). Smart stormwater management in urban areas by roofs greening. In International Conference on Computational Science and Its Applications (pp. 455-463). Springer, Cham

Mundoli, S., Unnikrishnan, H., Nagendra, H. (2017). The "Sustainable" in smart cities: ignoring the importance of urban ecosystems. Decision, 44(2), 103-120.

Neirotti, P., De Marco, A., Cagliano, A. C., Mangano, G., Scorrano, F. (2014). Current trends in Smart City initiatives: Some stylised facts. Cities, 38, 25-36.

Nitoslawski, S. A., Galle, N. J., Van Den Bosch, C. K., Steenberg, J. W. (2019). Smarter ecosystems for smarter cities? A review of trends, technologies, and turning points for smart urban forestry. Sustainable Cities and Society, 51, 101770

Okai, E., Feng, X., Sant, P. (2018, June). Smart cities survey. In 2018 IEEE 20th International Conference on High Performance Computing and Communications; IEEE 16th International Conference on Smart City; IEEE 4th International Conference on Data Science and Systems (HPCC/SmartCity/DSS) (pp. 1726-1730). IEEE.

Richardson, J. J., Moskal, L. M. (2014). Uncertainty in urban forest canopy assessment: Lessons from Seattle, WA, USA. Urban forestry \& urban greening, 13(1), 152-157.

Russo, A., Cirella, G. T. (2018). Modern compact cities: how much greenery do we need?. International journal of environmental research and public health, 15(10), 2180.

Sethi, M. (2015). Smart cities in India: challenges and possibilities to attain sustainable urbanisation. Nagarlok, 47(3), 20-37.

Shafique, M., Kim, R., Kyung-Ho, K. (2018). Green roof for stormwater management in a highly urbanized area: the case of Seoul, Korea. Sustainability, 10(3), 584.

Silva, B. N., Khan, M., Han, K. (2018). Towards sustainable smart cities: A review of trends, architectures, components, and open challenges in smart cities. Sustainable Cities and Society, 38, 697-713.

Tuerk, M. (2019). Smart Cities Are Going Green Because It Costs Less. Forbes. Retrieved from https://www.forbes.com/sites/miriamtuerk/2019/03/14/smartcities-are-going-green-because-it-costs-less/\#76a6c44940fe

Ucar, Z., Bettinger, P., Merry, K., Akbulut, R., Siry, J. (2018). Estimation of urban woody vegetation cover using multispectral imagery and LiDAR. Urban Forestry \& Urban Greening, 29, 248-260.

Wachsmuth, D., Angelo, H. (2018). Green and gray: New ideologies of nature in urban sustainability policy. Annals of the American Association of Geographers, 108(4), 1038-1056. 
The International Archives of the Photogrammetry, Remote Sensing and Spatial Information Sciences, Volume XLIV-4/W3-2020, 2020 5th International Conference on Smart City Applications, 7-8 October 2020, Virtual Safranbolu, Turkey (online)

Yigitcanlar, T. (2015). Smart cities: an effective urban development and management model? Australian Planner, 52(1), 27-34. 